\section{Un duelo sin despedida}

\section{Bereavement without farewell}

\section{Sr. Editor:}

No existe otra certeza más grande que la de saber que todos moriremos en algún momento. A pesar de esta realidad, los profesionales de la salud nos encontramos muchas veces con dificultades para hablar de la muerte con nuestros pacientes y no siempre tenemos claro cómo apoyarlos en su dimensión humana y espiritual, especialmente cuando la muerte sobreviene de manera inesperada. Esta experiencia es aún más dolorosa cuando apoyamos a padres que enfrentan la muerte de un hijo. En este contexto, quisiera compartir una experiencia personal, cuyo desenlace aún me produce sensaciones encontradas.

Era una lejana tarde de otoño, al interior de la sala de ultrasonido donde me desempeñaba haciendo ecografías obstétricas. No era fácil saber cómo transcurría el tiempo ahí dentro, sólo la lista de pacientes examinados daba una idea que estaba próxima a que terminara la jornada. Cuando llamé en voz alta el nombre de la última paciente, una señora se puso de pie y avanzó del brazo de un hombre de alrededor de cincuenta años. Dudé una fracción de segundo, pensando que tal vez venían a un control ginecológico y no a una ecografía obstétrica, pero luego reparé en el amplio vestido que ocultaba el vientre abultado de la mujer.

Mientras acomodaba en la camilla a la señora María (nombre ficticio), le pregunté si deseaban saber el sexo de la guagua.

- Sí doctora, por favor. Tenemos dos hijos hombres ya grandes y nos gustaría tanto que fuera una niñita -contestó el marido. Luego agregó: -Ésta fue una sorpresa, a nuestra edad no pensamos que podía ser un embarazo. Estamos tan ilusionados-...

La señora María tenía 44 años, multípara de dos, cursando un embarazo de 24 semanas, sin patología asociada. Mientras esparcía el gel, buscaba infructuosamente verificar viabilidad fetal. Seguí un par de segundos más, con el transductor apoyado suavemente en el abdomen de la mujer y los ojos fijos en la pantalla del ecógrafo. Completé el examen ecográfico, buscando determinar el tiempo transcurrido desde el fallecimiento in-útero y la posible presencia de eventuales malformaciones que pudiesen explicar la causa de muerte. Mientras, el matrimonio observaba mis movimientos con atención.
- Señora María, tenemos un problema con su guagua, el corazón no está latiendo- les dije, mientras intentaba buscar las palabras precisas.

- ¿Cómo que no late?- preguntó el marido, mientras la señora María seguía muda.

- Sí, el corazón se detuvo...

- ¿Y qué podemos hacer para que se mejore?preguntó él, con una voz esperanzada, confiado en que podría sugerirles algún tratamiento.

¿Cuál es la mejor manera de decirles que ha fallecido, que en realidad no hay nada que podamos hacer por el feto? ¿Qué palabras utilizar para atenuar el impacto de la noticia inesperada? Estas eran algunas de las preguntas que me formulaba, en silencio, mientras ayudaba a la señora María a incorporarse.

- Señora María, su bebé murió adentro suyo, no podemos hacer nada... Tiene que ir a Urgencia de la Maternidad, seguramente la dejarán hoy mismo hospitalizada. Lo siento mucho... -fue todo lo que pude decirles. Los vi irse mudos y cabizbajos, sosteniéndose mutuamente.

Aunque sólo había sido mi paciente por los escasos minutos que duró el examen de ultrasonido, al día siguiente decidí visitarla. María estaba todavía en pabellón, mientras el obstetra terminaba la revisión instrumental.

- Señora María, soy la doctora que le hizo la ecografía, quería saber cómo se siente- le dije a modo de saludo.

- Estoy bien, gracias. ¿Sabe?, era niñita...- me dijo, con voz entrecortada.

Guardé silencio unos breves instantes y luego le pregunté: - ¿Se alcanzó a despedir de ella?

María me quedó mirando, como si recién pensara que existía la posibilidad de ver a su hija fallecida.

- No me atrevo, doctora. ¿Puede usted verla por mí y decirme si está bien que yo la vea?- me dijo después de un largo rato.

- Sí, no se preocupe.

Me aproximé hacia el pequeño bulto que yacía envuelto en paños encima del mesón. Pensaba en la tremenda responsabilidad que me había sido conferida. ¿Con qué parámetros podía determinar si debía ser vista por su madre? ¿Cómo podría siquiera intuir las consecuencias que tendría para la señora María un sí o un no de mi parte?

Descubrí lentamente el pequeño cuerpo. Sin necesidad de darle vuelta, tomé mi decisión.

- No, señora María, es mejor así, que no la 
vea- le dije, mientras me despedía con un ligero beso en la frente.

Todavía me arrepiento de mi decisión. Si bien respeté su autonomía, aún ahora me cuestiono si en ese breve encuentro médico-paciente que se genera durante la consulta ecográfica, pude llegar a conocer lo que eran sus creencias y valores. Decidí por ella que era mejor que guardase en su mente la imagen preciada de la pequeña niña que ellos soñaron, en vez de enfrentar la realidad de ver a su hija con los signos de maceración que ocurren luego de la muerte fetal. Al hacerlo, le negué la posibilidad de tener una memoria visual de su hija, que contribuyera a su proceso de sanación ${ }^{1}$. Tomé esta decisión tratando de considerar el mejor bienestar de María; al hacerlo, ignoré que han habido importantes cambios en el cuidado de los padres que experimentan una pérdida fetal, desde una actitud protectora y de secretismo a la de reconocer las necesidades específicas para enfrentar un duelo ${ }^{2}$. En este sentido, es importante facilitar el recuerdo y la memoria de quien se va, evitando esconder su existencia. La pérdida perinatal genera un tipo único de duelo, puesto que el niño es una parte importante de la identidad parental ${ }^{3}$. El ayudar a los padres a hacer frente a esta pérdida, proporcionándoles maneras concretas de obtener recuerdos tangibles del niño muerto, o ayudándoles a organizar un funeral o un servicio religioso de acuerdo a sus creencias, debe ser siempre parte del cuidado obstétrico. Para lograr esto, debemos mejorar nuestras destrezas de comunicación, de tal modo de poder brindar un adecuado apoyo emocional ${ }^{4}$. Mientras desarrollamos estas habilidades, debemos también aprender a lidiar con nuestras propias emociones, de tal manera que no interfieran con el cuidado que debemos dar a nuestros pacientes.

Sofía P. Salas

Escuela de Medicina y Programa de Ética y Políticas Públicas en Reproducción Humana. Universidad Diego Portales. Santiago de Chile.

\section{Referencias}

1. Alexander KV. The One Thing You Can Never Take Away. MCN Am J Matern Child Nurs. 2001; 26 (3): 1237.

2. Zeidenstein L. Breaking the silence. Finding a voice for loss. J Nurse Midwifery. 1995; 40 (4): 317-9.

3. Callister LC. Perinatal loss: a family perspective. J Perinat Neonatal Nurs. 2006; 20 (3): 227-34.

4. Lalor JG, Devane D, Begley CM. Unexpected diagnosis of fetal abnormality: women's encounters with caregivers. Birth. 2007; 34: 80-8.

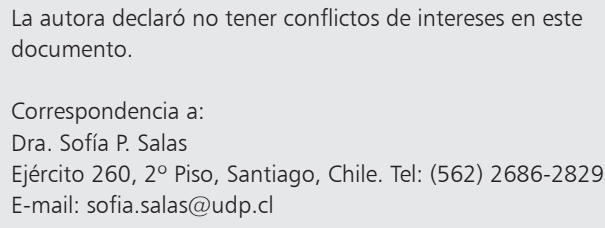

